\title{
Patients' Perception of the Benefits of Pharmaceutical Care Services in the Management of Hypertension in a Tertiary Health Care Facility in Benin City
}

\author{
PO Erah* and NA Chuks-Eboka
}

Pharmacotherapy Group, Faculty of Pharmacy, University of Benin, Benin City, Nigeria

\begin{abstract}
Purpose: Measuring the perceptions of patients is essential in evaluating the success of therapy and needs of patients. The objective of this study was to investigate patients' perceptions of the benefits of regular participation in pharmaceutical care services in the management of hypertension.

Method: In a cross sectional study, 285 systematically selected hypertensive patients attending consultant outpatient clinic in University of Benin Teaching Hospital, Benin City (UBTH) were interviewed on the benefits of pharmaceutical care services they received from pharmacists, susceptibility to health-related problems and threat reduction associated with regularly meeting with the pharmacists, using a validated structured interview format with reliability coefficient in the range of 0.79 to 0.87 .

Results: The patients rated medications supply and medication cost information provision as beneficial but rated patient education/counseling as fairly beneficial. However, patient monitoring, provision of nonmedication information and other specific information such as side effects, exercises, weight and blood pressure control were rated as "not beneficial". The services provided by the pharmacists in preventing/reducing health-related problems were poorly rated. While the perceived benefits and thread reduction were not associated with age, sex and education of the patients or the type of medication taken, patients perceived a significantly lower chance of developing health-related problem when they met with the pharmacists as compared to when they did not $(P<0.001)$.

Conclusion: Although the hypertensive patients studied perceived that pharmacists contribute to the reduction in hypertension-related problems, they do not currently benefit much from the level of services offered by the pharmacists. Therefore, pharmacists working in UBTH needs to develop and fully implement comprehensive pharmaceutical care and the Health Ministries should work in collaboration with the relevant professional bodies to ensure that there is effective pharmaceutical care services in all health care facilities.
\end{abstract}

Keywords: Pharmaceutical care, perceived benefits, threat reduction, perceived susceptibility, hypertension.

*Corresponding Author: E-mail: patrick.erah@gmail.com or p_erah@yahoo.com, Tel (234) 08023360318 


\section{INTRODUCTION}

In recent years, patient's opinion is increasingly considered to be a useful component in the determination of care outcomes ${ }^{1-6}$. Other than the dependence of continuity of patient-pharmacist relationship, and hence medication therapy outcomes on it, a patient's opinion directly influences his/her adherence to treatment ${ }^{7-9}$. Measuring the perceptions of patients presents concrete advantages for the evaluation of the success of therapy and patients' needs since patients constitute essential source of information about accessibility and effectiveness of care 10. Therefore, it has become indispensable to involve patients more in decisions that concern them ${ }^{11}$ and to better meet their expectations ${ }^{12}$ in the implementation of any care structure and plans.

Worldwide, hypertension is prevalent among older people with a substantial morbidity and mortality ${ }^{13}$. Of all the non-communicable diseases prevalent in Nigeria, hypertension is one of the most important treatable condition whose management is far from optimal ${ }^{14-15}$. The active involvement of pharmacists in the management of hypertension can improve its management 16-17. By taking direct responsibility for individual patient's medication-related needs, pharmacists can make unique contribution to the outcome of medication therapy and to their patients' quality of life. This new approach in patient care, defined by Hepler and Strand ${ }^{18}$ as the responsible provision of drug therapy for the purpose of achieving definite outcomes that improve a patient's quality of life, is known as pharmaceutical care ${ }^{19}$. Since the introduction of the term "pharmaceutical care" in the practice of pharmacy, studies have shown that the successful implementation of the care requires the active participation of patients ${ }^{20-}$ 21. Generally, even the most comprehensive services will be ineffective if patients do not show up for appointments or fail to adhere to their treatment and monitoring plan. Consumers are also more likely to participate in a health care service, or recommend that service, on the basis of its perceived benefits and costs ${ }^{20,22-23}$

While the satisfaction derived by hypertensive patients from medication therapy has been reported ${ }^{24}$, little is known about the satisfaction derived by patients in Nigeria from the pharmaceutical services offered by pharmacists to patients on antihypertensive medications. Therefore, this study evaluates hypertensive patients' perception of the benefits of pharmaceutical care services in the management of hypertension in University of Benin Teaching Hospital (UBTH), Benin City. Other than providing evidence on pharmaceutical care services currently offered in a Nigeria tertiary health care facility to the international community of researchers, this study will help the pharmacists in Nigeria to know the level of satisfaction patients derive from the services they currently offer to hypertensive patients and which areas to improve on. The outcome of the study can thus be applied in designing and implementing a programme for improving pharmaceutical care services offered to hypertensive patients in Nigeria.

\section{METHODS \\ Setting}

This study was carried out in the Consultant Outpatients Department (COPD) in University of Benin Teaching Hospital (UBTH), Benin City located in southern part of Nigeria. A 550-bed tertiary health facility with over 20 health departments offering both secondary and tertiary health care to residents of Benin City and four neighbouring States (Provinces), UBTH has an annual outpatient turnover of over 95,000 patients, 176 resident doctors, 18 registered pharmacists, and 84 medical consultants - three of which are consultant cardiologists at the time of this study. Two registered pharmacists were assigned routinely to the Pharmacy unit located in the COPD. Of the average 400 weekly turn over of patients attending the Consultant Outpatients Clinics (COPC), 32.5\% were hypertensive patients. The COPC was run on 
Mondays, Wednesdays and Fridays during which hypertensive patients were equally attended to.

\section{Sample and Procedures}

In a cross sectional study, systematically selected sample of adult hypertensive patients enrolled in outpatient consultant clinic for hypertension were interviewed by two registered Clinical Pharmacists as they waited for their appointments in COPC. The sample size of 285 patients used for this study was obtained using an appropriate statistical formula for estimating minimum sample size in health studies and adding more patients to the calculated sample size to account for nonand in-complete responses ${ }^{25-26}$. Included in the study were adult male and female patients on antihypertensive medications for more than 6 months at the time of study. All the patients with history of stroke, and/or older than 65 years were excluded. The selection of the study sample (and subsequent interview) was done within a period of 3 months with 15 patients selected by systematic sampling from a listing of those scheduled for appointment on two (Mondays and Wednesdays) of the weekly clinics days until 285 patients could be interviewed (taking into account those that did not show up on appointment days). The purpose of the interview and confidentially of the information to be provided by the patients was explained to each patient that was approached to participate in the study.

The selected patients were interviewed in the patients' waiting area in COPC using a pretested, structured interview format with mostly closed-ended questions after obtaining informed consent from the participants and permission from the hospital management. Information obtained included sociodemographic characteristics of respondents and relevant measures of pharmaceutical care.

\section{Pharmaceutical care measures}

The components of the interview format used in this study included measures of the respondents' frequency of blood pressure
(BP) determination, health-related problems, current medications, as well as the patients' perceptions of the benefits of pharmaceutical care service components, susceptibility to health-related problems, and threat reduction associated with participation in pharmaceutical care services.

\section{Perceived benefits of service component -} The patients were asked to rate their perceptions about the benefits of antihypertensive medications-related pharmaceutical care using a 4-point scale from 1 "not beneficial", 2 "fairly beneficial", 3 "beneficial" to 4 "very beneficial ${ }^{27}$.

Perceived threat reduction - Respondents (patients) were asked to rate services provided by pharmacists in terms of reducing threat to developing sustained elevated blood pressure, stroke, insomnia, obesity, low libido, and other complications, in relation to the pharmaceutical care services being provided by the pharmacists on a scale of 1 to 5 , with higher scores indicating greater perceived threat reduction as previously reported ${ }^{27}$. Scores below 3 (mid-point) were considered to represent poor services.

Perceived susceptibility - This measured the patients' perceptions of the likelihood of experiencing medication-related problems during the periods when they were regularly visiting the pharmacists. Patients were asked to rate their perceived likelihood of experiencing reduction in medication-related problems if they did not meet with the pharmacists on a regular basis as well as the likelihood of experiencing the problems if they did meet with the pharmacist on a regular basis on a score of 1 to 5 , with higher scores indicating greater reduction in perceived susceptibility. The difference between these two conditional perceived susceptibilities (susceptibility gap) should reflect the perceived increased risk of developing medication-related problems when the patient fails to participate in pharmaceutical care services and should influence the perceived benefits of the services ${ }^{20,27-28}$. 


\section{Data analyses, validity and reliability}

Data validity was assured by carefully selecting items suggested from previous studies and the researcher's personal experience ${ }^{16,20,27,29}$. The reliability of the data was determined by administering the interview format twice to a set of 30 patients selected at random and the reliability coefficients for the pre-test and post-test were determined using Cronbach's alpha. The pre-test and post-test reliability coefficients for the data ranged from 0.79 to 0.87 .

The data collected from the respondents were coded and entered into the computer using computer software, Epi-info 2003 (CDC, USA/WHO, Geneva) which was also used for all statistical analyses. Data entered into the computer were double-checked to ensure accuracy. Descriptive statistics (frequency and percentages, categorized by gender and age) were employed in presentation of sociodemographic data. The mean scores for the measured items were calculated to determine the relative perceived benefit, threat reduction or susceptibility and expressed as mean and standard deviations as appropriate. Proportional data were compared using chi-square test or Fisher's exact test, as appropriate while the differences between mean scores were evaluated using the Student $t$ test for paired data. Pearson correlation was used to evaluate the relationship between the sociodemographic data and antihypertensive medication with the service component benefits as well as perceived threat reduction. The criterion for statistical significance was 95\% confidence interval and 2 -tailed $P$ values less than 0.05 .

\section{RESULTS}

\section{Socio-demographic characteristics of respondents}

The distribution of age, sex and educational qualifications of the 285 patients (representing $81 \%$ of the total number of patients initially scheduled for interview) that were interviewed are provided in Table 1 . Majority of these patients $(79.9 \%)$ were older than 45 years while only $23.2 \%$ had either primary or no formal education. Over $50 \%$ of them had tertiary education. The patients in the age range of $26-35$ years were only $4.2 \%$. There was no significant difference between the number of males and females interviewed $(P=0.12)$ but there was gender differences in their educational background $(P=0.002)$.

\section{Clinical variables}

Blood pressure (BP) measurement by patients: Majority of the patients interviewed $(51.6 \%)$ had their BP measured only when they came for routine check up in the clinic on appointment days which was usually every 2 months while $21.0 \%$ of them routinely measured their blood BP at home (once a week). Only $15.8 \%$ of the patients monitored their BP very often (2 to 3 times a week) while $10.5 \%$ measured their BP measurement seldomly.

Patients' medications: Calcium channel blockers (nifedipine and amlodipine) topped the list of medication (55.8\%) used by the patients, and this was followed by Aspirin 75mg (45.3\%) and diuretics (39\%) (Table 2). Moduretic $^{\circledR}$ (a combination of amiloride and hydrochlorothiazide), nifedipine and propranolol (prescribed in 3-4\% of cases) were the most commonly used monotherapeutic antihypertensive agents, accounting for $66.1 \%$ of the overall medications prescribed. Dual therapy with methyldopa frequently combined with either Moduretic ${ }^{\circledR}$ or nifedipine accounted for $48.2 \%$ of the antihypertensive medications. For triple therapy with antihypertensive agents, methyldopa, Moduretic ${ }^{\circledR}$, nifedipine and propranolol occurred in 47.5\%, 42.7\%, 51.9\% and $22.9 \%$ of the prescriptions, respectively. Other antihypertensive medications that were being used by the patients included hydralazine (1.2\%), reserpine/ clopamide/ dihydroergocristine combination - Brinerdin ${ }^{\circledR}$ (4.7\%), Lisinopril (6.2\%), practolol (8.5\%), prazosin/polythiazide combination - Minizide ${ }^{\circledR}$ (13.5\%). There was no association between the type of medication being used and the 
Table 1: Age, sex and educational background of responding patients $(n=285)$

\begin{tabular}{cll}
\hline & Male (\%) & Female (\%) \\
\hline Age (years) $^{\mathrm{a}}$ & $7(2.5)$ & $13(4.6)$ \\
$26-35$ & $19(6.7)$ & $22(7.7)$ \\
$36-45$ & $56(19.6)$ & $71(24.9)$ \\
$40-60$ & $56(19.6)$ & $41(14.4)$ \\
$61-65$ & $138(48.4)$ & $147(51.6)$ \\
Total & & \\
& & $18(6.3)$ \\
Educational qualification ${ }^{\mathrm{b}}$ & $6(2.1)$ & $27(9.5)$ \\
No formal education & $15(5.3)$ & $42(14.7)$ \\
Primary & $33(11.6)$ & $60(21.0)$ \\
Secondary & $84(29.5)$ & $147(51.6)$ \\
Tertiary & $138(48.4)$ & \\
Total & ${ }^{a} \chi^{2}=5.83, d f=3, P=0.12 ;{ }^{b} \chi^{2}=14.24, d f=3, P=0.0 .003$
\end{tabular}

Table 2: Patients' medications

\begin{tabular}{ll}
\hline Medication Taken & Proportion of patients (\%) \\
\hline Calcium channel blockers (nifedipine, amlodipine) & 55.8 \\
Aspirin & 45.3 \\
Diuretics (Moduretic ${ }^{\circledR}$, frusemide, spironolactone) & 39.0 \\
Centrally acting antihypertensive agents (methyldopa) $_{\text {ACE Inhibitors (captopril) }}$ & 29.9 \\
Beta blockers (propranolol) & 17.9 \\
Others & 16.8 \\
\hline
\end{tabular}

rating of the service components or threat reduction.

\section{Health-related problem experienced by respondents}

Other than high blood pressure and edema, hypertension-related problems reported to have been experienced by the patients were fatigue $(55.8 \%)$, shortness of breath $(9.5 \%)$, restlessness (22.1\%), and low libido (13.7\%). Others included insomnia, weakness, and anxiety. Most of the patients had experienced more than one problem since the inception of the diagnosis of their hypertension.

\section{Perceived benefits of service component}

The patients rated supply of medicines and providing information on cost of medications as beneficial (Table 3). Patient education/counseling, and provision of medication information were generally rated as fairly beneficial. However, patient monitoring and provision of non-medication information as well as specific education and counseling on medication interactions, side effects, exercises, weight control, blood pressure control, healthy living, reduced salt intake, and anxiety were rated as "not beneficial" (score approximately or below 1). Age, sex and educational levels did not correlate with the scores of the benefits of service components. 
Table 3: Rating of the level of pharmaceutical care (PC) services provided by pharmacists and what the respondents expected to have been provided $(n=285)$

\begin{tabular}{ll} 
PC service Components & $\begin{array}{l}\text { Rating of services provided on } 4 \\
\text { point scale (mean } \pm \text { SD) }\end{array}$ \\
\hline Supply of medicines & $3.45 \pm 0.9$ \\
Monitoring of patients & $0.70 \pm 0.2$ \\
Providing drug information to patients & $1.34 \pm 0.4$ \\
Providing non-drug therapy information & $0.79 \pm 0.3$ \\
Education and counseling of patients & $1.56 \pm 0.4$ \\
& \\
Specific educating and counseling on: & \\
Use of medications & $2.01 \pm 1.3$ \\
Medication interactions & $0.92 \pm 0.3$ \\
Medication cost & $3.28 \pm 0.4$ \\
Side effects of medications & $1.03 \pm 0.4$ \\
Drinking of alcohol & $0.75 \pm 0.4$ \\
Exercises & $0.70 \pm 0.3$ \\
Weight control & $0.80 \pm 0.3$ \\
Blood pressure control & $0.83 \pm 0.5$ \\
Healthy eating plan & $0.81 \pm 0.3$ \\
Reduced salt intake & $0.86 \pm 1.4$ \\
Anxiety & $0.75 \pm 0.4$ \\
\hline
\end{tabular}

Table 4: Rating of pharmaceutical care services provided by pharmacist in terms of reducing threat to developing common hypertension-related problems $(n=285)$

\begin{tabular}{ll}
\hline Problem & $\begin{array}{l}\text { Rating of perceived threat reduction } \\
\text { on a scale of 5 points (mean } \pm \text { SD) }\end{array}$ \\
\hline Insomnia & $1.92 \pm 1.1$ \\
Stroke & $1.98 \pm 1.2$ \\
Sustained elevated blood pressures & $2.35 \pm 1.1$ \\
Low libido & $1.74 \pm 1.1$ \\
Obesity & $2.04 \pm 1.1$ \\
Other possible complication & $1.88 \pm 1.1$ \\
\hline
\end{tabular}

\section{Perceived threat reduction}

The importance of pharmaceutical care services provided by the pharmacists in preventing/reducing insomnia, stroke, sustained elevated blood pressure, low libido, obesity and other possible complications such as heart attack, organ damage, etc. for the patients was generally rated low as the overall mean score was less than 2.5 on the 5-point scale (Table 4). Thread reduction rating was not associated with age, sex and education of the patients or the type of medication taken.

\section{Perceived susceptibility}

The mean score and SD for the perceived susceptibility for medication-related problems 
when the patients with meet the pharmacists and when they did not meet with the pharmacists are $2.73 \pm 0.7$ and $4.67 \pm 0.49$, respectively. The patients perceived a significantly lower chance of developing medication-related problems when they meet with the pharmacists as compared to when they did not $(P<0.001)$ and the perceived susceptibility gap was $1.93 \pm 0.59$. A greater risk of developing medication-related problems was thus perceived by the patients if they do not participate in pharmaceutical care as compared to regular participation in pharmaceutical care provided by pharmacists for hypertensive patients.

\section{DISCUSSION}

The proportion of males involved in this study was not significantly different from those of the females implying that the data applied in the interpretation of the results were not gender bias. Therefore, the rating of the services provided by the pharmacists were not interpreted on the basis of gender unless appropriate. For majority of the patients, ambulatory measurement of blood pressure (BP) was not a common practice. The $51.8 \%$ of the patients who relied on their BP being measured only when ever they went to the hospital were most likely unaware that monitoring BP over a period of time at home can provide the pharmacist, doctor or nurse with more information on the effectiveness of their treatment. BP values measured in the clinic are subject to the so called 'white coat hypertension (WCH)' - a condition in which there is a transient rise in BP levels in the presence of a health professional - that can lead to between $10-20 \%$ of inappropriate antihypertensive medication therapy ${ }^{30-31}$. It is therefore important that the pharmacists should adequately counsel hypertensive patients on the fact that ambulatory measurement of BP is an accepted method of attempting to deal with $\mathrm{WCH}^{32}$. All the healthrelated problems presented by the patients interviewed are known problems associated with hypertension ${ }^{33}$.
Patients may often judge the benefits of pharmaceutical care on the basis of the ability of the care provider to reduce the threat of pertinent health problems ${ }^{20}$. In this study, the patients have generally rated the services provided by the pharmacists poorly. Specific information on medication and other healthrelated problems including side effects, weight and blood pressure control, etc that can enhance medication therapy were hardly discussed with the patients. If this result is evaluated in line with an earlier study on patient-pharmacist communication in Benin City ${ }^{34}$, it becomes apparent that the pharmacists involved in managing the patients offered only basic pharmaceutical care services that concentrate on simply supplying prescribed medicines to patients. This was confirmed when the registered pharmacists attending to the patients were observed over a period of 5 working days dispensing medications. In most instances, majority of the pharmaceutical service components were only provided when the pharmacists were prompted by patient-question asking 34 . Through observation and interaction with all the registered pharmacists in the health facility, it became obvious that the number of pharmacists in the facility were grossly inadequate and there were no counseling rooms for effective patient education and counseling.

Consistent with Nau's rating ${ }^{28}$ of perceived threat reduction, patients' assessment of the perceived threat reduction is based on the likelihood of developing health-related problems when visiting the pharmacist regularly versus the likelihood of developing health-related problems when they did not visit regularly. The wider the gap in the perceived likelihood of experiencing health problems between the conditions of participation or nonparticipation in the clinic services, the greater the perceived threat reduction ${ }^{28}$. An important finding in this study was that patients perceived themselves to be at a lower risk for developing insomnia, stroke, sustained elevated blood pressure, low libido, obesity and other possible complications of 
hypertension such as heart attack, organ damage, etc. if they met with the clinic pharmacist on a regular basis. This is an implication that patients perceive a decrease in the likelihood of experiencing medicationrelated problems through participation in pharmaceutical care. Thus, the patients perceive the pharmacist as a health care professional that can positively contribute to the improvement of their quality of life. Since the patients think that their risk of healthrelated problems will be reduced through regular interactions with the pharmacist, they are very likely to actively participate in pharmaceutical care activities.

\section{CONCLUSION}

The most beneficial pharmaceutical care component offered to patients' attending antihypertensive clinic in the facility studied are the supply of medication and provision of information on cost of medication. Although the patients perceived a significantly lower chance of developing medication-related problems when they meet with the pharmacists as compared to when they did not, their perception of the pharmacist in reducing threat to health-related problems in the management of hypertension is generally poor.

More frequent and meaningful interactions with patients will increase pharmacists' opportunities to contribute to improved patient outcomes. Therefore, pharmacists in UBTH needs to fully embrace pharmaceutical care and the Health Ministries should work in collaboration with the relevant professional bodies to develop and implement effective pharmaceutical care services not only in UBTH but in all other health care facilities.

\section{REFERENCES}

1. Palmer $R H$. Considerations in defining quality of care. In Palmer RH (ed.). Striving for Quality in Health Care: An Inquiry into Policy and Practice. Ann Arbor: Health Administration Press 1991:1-59.

2. Williams, $S$, Calnan $M$. Convergence and divergence: assessing criteria of consumer satisfaction across general practice, dental and hospital care settings. Social Sci Med 1991;33:707-16.

3. Ford RC, Bach SA, Fottler MD. Methods of measuring patient satisfaction in health care organizations. Health Care Manag Rev 1997;22:74-89.

4. Donabedian A. The Definition of Quality and Approaches to its Assessment. Vol. 1. Ann Arbor: Health Administration Press, 1980.

5. Donabedian A. Defining and measuring the quality of health care. In Wenzel RP (ed.). Assessing Quality Health Care. Perspectives for Clinicians. Williams and Wilkins, Baltimore, 1992.

6. Rosenthal GE, Shannon SE. The use of patient perceptions in the evaluation of health-care delivery systems. Med Care 1997;35(11 Suppl):NS58-68.

7. Ware J, Hayes R. Methods for measuring patient satisfaction with specific medical encounters. Med Care 1988;26:393-402.

8. Pascoe G. Patient satisfaction in primary health care: a literature review and analysis. Eval Program Planning 1983;6:185-210.

9. Rubin $H$. Can patients evaluate the quality of hospital care? Med Care Rev 1990;47: 267326.

10. Donabedian $A$. The role of outcomes in quality assessment and assurance. Qual Rev Bull 1992;18:356-60.

11. Calnan M. Lay evaluation of medicine and medical practice: report of a pilot study. Int $\mathrm{J}$ Health Serv 1988;18:311-22.

12. Calnan MW. The patient's perspective. Int J Technol. Assess Health Care 1998;14:24-34.

13. Amery $A$, Birkenhager $W$, Brixko $P$, Bulpitt $C$, Clement $D$, Deruyttere $M$, De Schaepdryver A, Dollery C, Fagard R, Forette F, Forte J, Hamdy $R$, Henry JF, Joossens JV, Leonetti G, LundJohanssen $P$, O'malley $K$, Petrie $J$, Trasser $T$, Tuomilehto J, Williams Bl. Mortality and morbidity results from the European working party on high blood pressure in the elderly trial. Lancet 1985;1:1349-54.

14. Luscher TF, Vetter $H$, Slegenthaler $W$, Vetter $W$. Compliance in hypertension: facts and concepts. J Hypertens Suppl 1985;3(1):3-9.

15. Federal Ministry of Health, Nigeria (FMOH). Noncommunicable diseases in Nigeria: Final report of a national survey by the National Expert Committee on Non-Communicable diseases, 1997, pp 14-41.

16. Park JJ, Kelly $P$, Carter BL, Burges PP. Comprehensive pharmaceutical care in the chain setting. JAM Pharm Assoc 1996;S36;443-51.

17. Erickson SR, Slaughter R, Halapy H. Pharmacists' ability to influence outcomes of hypertension therapy. Pharmacother 1997;17;140-7.

18. Hepler CD, Strand LM. Opportunities and responsibilities in pharmaceutical care. $A m \mathrm{~J}$ Hosp Pharm 1990;47:533-43. 
19. World Health Organization (WHO). Developing Pharmacy Practice: A focus on Patient Care. WHO/PSM/PAR/2006.5, 2006.

20. Nau DP, Read LD, Lipowski EE. What makes patients thing that their pharmacists' services are of value? JAM Pharm Assoc 1997; NS37:91-8.

21. Cippole RJ, Strand LM, Morley PC. Pharmaceutical Care Practice. McGraw-Hill, New York, NY, 1998:246-7.

22. Boulding $W$, Kalra $A$, Staelin $R$, Zeithaml VA. A dynamic process model of service quality: from expectations to behavioral intentions. J Market Res 1993; 30:7-27.

23. Reuben $D B$, Posey E, Hays RD, Lim ME. Predictors of patient refusal to participate in ambulatorybased comprehensive geriatric assessment. J Gerontol 1994; 49:M209-15.

24. Chen K, Chiou CF, Plauschinat CA, Frech F, Harper $A$, Dubois R. Patient satisfaction with antihypertensive therapy. J Hum Hypertens 2005; 19(10):793-9.

25. Araoye MO. Research Methodology with Statistics for Health and Social Sciences. Nathadex Publishers, Illorin, Nigeria, 2004, pp 115-120.

26. Brown RA, Beck JS. Medical Statistics on Personal Computers. 2 edn. BMJ Publishing Group, UK, 1995.

27. Nau DP, Ried LD, Lipowski EE, Kimberlin C, Pendergast CJ, Spivey-Miller S. Patients Perceptions of the Benefits of Pharmaceutical Care. J Am Pharm Assoc 2000; 40(1):36-40.
28. Nau DP. A Perceived Value Framework for Explaining Patients Intension to Use Pharmaceutical Care Services (dissertation) Gainsville, Fla: University of Florida, Florida, USA, 1997.

29. Oparah CA, Iwuagwu MA. Public perception of community pharmacists in Benin City, Nigeria. Int J Pharm Pract. 2001;9:191-5.

30. Staessen JA, O'Brien ET, Thijs $L$, Fagard $R H$. Modern approaches to blood pressure measurement. Occup Environ Med 2000; 57:510-20.

31. Selenta C, Hogan BE; Linden W. How Often Do Office Blood Pressure Measurements Fail to Identify True Hypertension? Arch Fam Med 2000; 9:533-40.

32. Jaylett $M$. Ambulatory or self blood pressure measurement? Improving the diagnosis of hypertension. Fam Pract 1994; 11(2):197-200.

33 Aguwa CN. Hypertension. In: Aguwa CN (ed). Therapeutic Basis of Clinical Pharmacy in the Tropics, $3^{\text {rd }}$ edn. SNAAP Press Ltd., Enugu, Nigeria, 2004, pp. 102-39.

34. Erah PO, Bafor EE. Assessment of pharmacistpatient communication in some health care facilities in southern Nigeria. Nig J Pharm Sci 2004; 3(1):23-34 